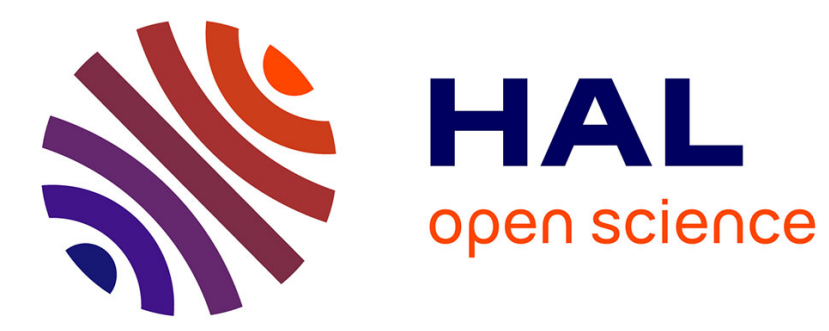

\title{
Amateurs' Exploration of Wine: A Pragmatic Study of Taste
}

\author{
Genevieve Teil
}

\section{To cite this version:}

Genevieve Teil. Amateurs' Exploration of Wine: A Pragmatic Study of Taste. Theory, Culture and Society, 2021, 38 (5), pp.137 - 157. 10.1177/02632764211029347 . hal-03507418

\section{HAL Id: hal-03507418 \\ https://hal.inrae.fr/hal-03507418}

Submitted on 3 Jan 2022

HAL is a multi-disciplinary open access archive for the deposit and dissemination of scientific research documents, whether they are published or not. The documents may come from teaching and research institutions in France or abroad, or from public or private research centers.
L'archive ouverte pluridisciplinaire HAL, est destinée au dépôt et à la diffusion de documents scientifiques de niveau recherche, publiés ou non, émanant des établissements d'enseignement et de recherche français ou étrangers, des laboratoires publics ou privés.

\section{(1) (1) $\$$}

Distributed under a Creative Commons Attribution - NonCommercial - NoDerivatives $\mid 4.0$ 


\title{
Amateurs' exploration of wine- A pragmatic study of taste
}

\author{
Teil, Geneviève
}

UMR SADAPT, INRA, AgroParisTech, Université Paris-Saclay, 75005, Paris, France genevieve.teil@agroparistech.fr

published version: Teil, Geneviève (2021). Amateurs' exploration of wine - A pragmatic study of taste. Theory Culture \& Society, 38(5, September 2021), 137157. $10.1177 / 02632764211029347$

\section{Abstract (150-word abstract)}

Amateurs are neither regular consumers nor professionals. What makes them distinctive? To answer that question, this ethnographic study focuses on wine amateurs, who show a distinctive feature compared to regular consumers: for them, wine is not a straightforward reality, but a world to explore.

Wine exploration drives an evolution that transforms both wine and amateurs' disposition towards it. Amateurs usually start with the discovery of the wines and their tastes, which may turn into an ability to tune and finally produce taste and good quality. Amateurs' passion, initially fuelled by the discovery of unknown tastes, is then informed by the renewal of the taste experience itself.

Following amateurs in their exploratory activity allows us to extend the analysis beyond scholars' usual focus on one of its particularly normative stages, and to propose a renewed account of the amateur that is quite remote from the standard image of the 'cultural prescriber'. Keywords: sociology of taste, pragmatism; taste; amateurs; wine; quality 


\section{Introduction}

Amateurs have long been described as enjoying an uncomfortable place between production and consumption. Compared to 'regular' consumers, they show unusual focused interests, knowledge, tastes and spending. Yet however skilled and knowledgeable amateurs may be, they can hardly be seen as professionals: they do not fit professional proficiency standards (Majumdar, 2017) nor pursue professionalization aims; instead, they defy its rules, codes, and constraints (Dubois et al., 2013), as well as professional (Flichy, 2012) and economic competition (Stebbins, 1977, 1979, Platt, 2000).

In placing taste, "the art of making differences", next to economic power at the core of class differentiation, (Bourdieu, 1979, 1992) has proposed an enriched understanding of the social differenciation process, ceaselessly fuelled and renewed by production, through an embodied dialectic play between imitation and distinction. His notion of 'cultural intermediary' experienced great success and inspired a good number of culture studies on taste construction, ranking and legitimization (Negus, 2002, Wright, 2005, Smith Maguire and Matthews, 2014, Jamerson, 2009). By overcoming the divide into consumption and production, sociology of taste has contributed to a more comprehensive integration of amateurs.

Within consumption products, wine has warranted particular interest due to the assumed preeminence of its symbolic value. While some scholars have scrutinized the role of wine retailers (Howland, 2013) or wine language (Silverstein, 2006, 2016) in fuelling social distinction, others have insisted on the socially-constructed 'discourses' (Rössel et al., 2018, Smith Maguire, 2018), the particular 'conventions' or 'normative knowledge' regarding quality (Terrio, 2000) and supporting social stratification (Groves et al., 2000, Jamerson, 2009, Overton and Murray, 2013, Beckert et al., 2017, Abbots, 2018). Amateur wine consumption reveals a range of singular practices: amateurs use guides for choosing wines, cellars for storing, thermometers, decanters, spittoons, pouring devices and a variety of glasses for drinking, notebooks for taking notes, etc., which de Benedittis (2019) and Schwarz (2013), emphasizing tasting in addition to taste, interpret as mediating an underground socio-cultural differentiation. Wine amateurs, however, as distinct from consumers, have rarely been studied, though Smith Maguire (2010) underlines their contribution to taste legitimation and socially-constructed norms as "taste leading consumers".

Still, this focus on legitimization or social stratification has raised criticism. It fosters a selective choice of the relevant data on which to elaborate an account of the amateurs' activities, which 
overlooks the purpose of using such linguistic and material devices, as well as decisive technical choices regarding blind tasting for instance; and it erases the uncertainties of the tasting experience and learning process, and oversimplifies the role of taste (Entwistle, 2006). These analyses appear therefore to come from 'strangers', or observers who do not 'share' the amateurs' experience, and to show an apparently purposeless activity. While the resulting point of view may fit the taste objectification underlying private concierge occupation (Sherman, 2011), it does not do full justice to the complexity of amateurs' activity, and even result in "claims made by analysts who are themselves engaged in social projects" (DeNora, 1995). Furthermore, as Cowen (1989) and Hennion (2001) have emphasized, they consider taste, though constructed, as unproblematic data which, in the case of amateurs and as this study will confirm, is highly questionable.

Amateurs' interest for taste has, in contrast, provided rich ground to dissenting scholars to argue the need for less critical and more comprehensive scrutiny (Holt, 1995, Hennion, 2001). Vannini et al. (2010) offer an interesting attempt to transform taste data into tasting accounts embedded in social activities. Pursuing Hennion and Teil (2004) focus on 'attention', Sternsdorff Cisterna (2014) opposes the attentive 'tasting' of wines, an "active engagement aimed at creating, comparing and storing sensorial knowledge", to usual 'sampling', an "act of drinking where people may or may not pay active attention to the sensorial cues of the wine". In these alternative studies, amateurs' drinking emerges as a reflexive and talkative practice generating taste and pleasure (Teil and Hennion, 2004, Sneijder and te Molder, 2005, Teil, 2009), where practice transforms the amateur and vice versa. Tastes move on from 'phase' to 'phase', recorded as noticeable moments of the amateur's 'trajectory' or 'career' (Becker, 1963, Lizé, 2012, Sternsdorff Cisterna, 2014). This pragmatist stance opens a new perspective on cultural practices.

\section{Studying amateurs}

This article offers a comprehensive account of wine amateurs' passionate activity and of the taste transformation that it fosters. Though wine producers may also be wine amateurs, they are very rarely prosumers in Toffler (1980)'s sense: consumers engaged in wine production. Neither do they match Barthes's 'active' music amateur whose instrument practise supports a more complete access to music, yet one that is free of competition and mastery constraints. Wine amateurs nevertheless show an extreme and central interest in perception, which seeps through the ethnographic studies of their activity (Vannini et al., 2010, Demossier, 2010, 
Gravina, 2012, Perullo, 2012, Tomasi, 2012, Sternsdorff Cisterna, 2014, Zhang, 2018). I have therefore used taste as an essential entry point to the study of the wine amateurs.

In addition to the abundant literature available to wine amateurs, particularly numerous guides on wine tasting and quality, this article draws on decades of participant observation with wine amateurs and wine professionals from Spain and France. I started a socioeconomic study of the quality wine market about 30 years ago, as a young amateur. To master the technical elements regarding wine, I took a viticulture and oenology degree, which allowed me to meet diverse actors involved in the wine market. The role of amateurs quickly raised my attention, along with wine critics, and they remained the focus of decades of fieldwork. Wine classes, fairs, tastings and shops were the ground for participant observation, and I conducted in-depth and sometimes repeated interviews with self-proclaimed amateurs and the acquaintances they shared their passion with. In one case, to get a broader understanding of the interviewee's practice, we met on a regular weekly basis for seven months. Until recently I never stopped meeting wine amateurs and professionals, though the focus of my research broadened to the more general functioning of the wine quality market. My initial collection of recorded and typed interviews grew from forty at the end the '90s to hundreds by 2010. I have also engaged in comparing wine with music (Maisonneuve et al., 2002) and more anecdotally other passions (ten interviews).

During the field work, I purposely avoided reducing amateurs to their tastes and practices, focusing instead on their 'activities' in the widest sense. I was careful not to excessively distance myself from my interlocutors, and never introduced myself as a sociologist $\mathrm{t}^{\mathrm{i}}$. (Hennion, 2007, Benzecry, 2012, Whittenburg Ozment, 2015, van den Haak and Wilterdink, 2019) have underlined that amateurs are themselves often very much aware of the sociological critique of tastes (Dannefer, 1981), and interviews with sociologists could over-emphasize social concerns (Hennion, 2001). My own amateur practice played an important role: interviews were always discussions between amateurs, supported by 'interesting' wines to taste, and could last for several hours. My questions focused primarily on the experience of wine tasting and amateur practice, their various aims and achievements, noticeable events, changes etc., and secondarily on what being an 'amateur' meant. Whereas conversations with non-amateurs often revolve around the 'conventional' nature of tasting practices, my interviews never raised such topics. Only sometimes did I discuss whether X or Y were 'real' amateurs or not, and what this could mean. As amateurs do not form a homogeneous set, my quest has been to identify the variety of ways of being a wine amateur. 
The present analysis proceeds from a strictly pragmatist perspective, removed from actor's theories on taste and amateurs. I rejected the psychologization of amateurs as 'curious' or 'sybarite' namely, as well as the pervasive psychophysical understanding of perception and its influences, and adopted a strictly phenomenal point of view on perception. Taste, gender, age, and social habitus, as well as the tasting occasion, place and season, opportunistically fuel amateurs' discussion of tasting discrepancies. Still, this study has not examined how taste is determined or who tasters are, but how their tastings are embedded in a passion-fuelled activity. Interview citations are therefore contextualized within this activity and not in other sociological 'contexts', although this does not preclude sociological or gender analysis of amateurs.

There are many non-exclusive aims and ways of enjoying wine. This article reserves the word 'amateur' to these particular reflexive drinkers who want to discover a world full of promises and therefore engage in wine exploration, an activity that slowly or suddenly transforms them, as well as their practices. Unlike 'connoisseur', the word 'amateur' insists on the fact that the activity is not just a matter of knowledge and skills, as suggested by the French definition, or of "making sense of a complex world" (Demossier, 2005). As this article shows, although the search for knowledge might fuel the amateur's quest, s/he is not just a scholar or collector (Mount, 2006).

Amateurs' quest unfolds in various ways, sometimes in sequential 'phases': the discovery of the wine world; the search for good quality; the production of good taste; the expectation of surprise. Due to textual linearity constraints, they are presented as a series of next steps between which amateurs can switch. Though frequently observed, this order is never a necessity: amateurs may skip steps or go backwards, depending on the unfolding of their tasting experience and their interpretation of the ongoing events. Lastly, they do not adopt a passion for life; they may drop it at any point, should it wane or be seen as leading nowhere.

\section{Discovering wine and good wines}

As Lou (an interviewee) points out, to be a wine amateur means having "the taste, passion, appetite for discovery. The discovery, the hunt, the quest. That's all”. Being 'curious' and 'open-minded' is a requirement found in the introduction to most guides and in all interviews. Yet this is not a psychological predisposition required to be an amateur, any more than wine can be said to be interesting, fascinating, or pleasing in and of itself. It simply correlates with 
the quest in which amateurs engage: an exploration of the world of wine, fed by the diversity that it elicits.

I still have something from those tasting sessions, which is having certain reference points for smells and having developed this taste... and this aspect of geography, entertainment, interest; you feel like you're opening up to a sense and discovering things. That's what's really fascinating. (Andrea)

Amateurs do not share tastes but a same taste quest. Wine guides and their large selections of wines support this exploration. In her study on wine consumption renewal, Demossier (2005) cites Mrs. Montalbetti, editor of the famous Hachette Guide of French Wines, who stresses its important role: 'to prescribe a search for diversity of taste'.

This quest for variety in wines must indeed be as open as possible. Habits, which constitute obstructions to discovery, must therefore be overcome:

Getting to know your body, getting to know your tastes, knowing how to increase your gustatory experience every day to try new things. Not remaining bound to a type of cuisine, a type of wine. Because in the end, that results in people who are totally closed, who aren't open-minded... (Alex)

Amateurs participate in an increasing number of tastings; they discover, share and exchange wines. They set up cellars in which they store their discoveries and good wines from which they hope to derive pleasure, and get other amateurs to taste them. Their exploration of wine is kindled by a quest for variety and for good wines: "we try to understand why something can be good and how it can be better, and how to assess the different qualities of these different types of wine" (Lou). They purchase guides and enrol in tasting courses. To better perceive the quality of wines, they acquire increasingly sophisticated tasting instruments, such as decanters to oxygenate young wines or decant old ones, glasses that intensify aromas, thermometers to check temperature, and spittoons to delay the effects of alcohol.

Along with the acquisition of knowledge on wine, some of them look for good deals, thus trying to soften the economic constraints of purchasing wine. Based on wine guides and ratings, they seek out advantageous quality-price differentials and malfunctions in the market. They stay one step ahead of reputations, find small, forgotten producers or follow auction sales to build prestigious collections at a lower cost.

Wine-lovers usually share their passion. 
Because another aspect is that of sharing, of being a collector and sharing your passion. Because not anybody can do it, because they don't have a cellar to store and collect. So, there's this desire to first of all show what you know, to show what you like, and to share and discover together what I would call impressions. (Lou)

Amateurs taste rare, expensive, famous, or prestigious wines and discuss with one another what each person discovers, likes, or feels is missing. They perform new experiments and repeat past experiences. "There's a prerequisite: you have to like wine, have a taste for wine, like to talk about it, collect it, and ultimately share it." (Lou). Gifting and sharing good wines are also a test of one's choices as a buyer and one's tasting skills.

Back when I used to go there [a wine fair] to discover wine, I would taste them all... I didn't take notes. I knew, well, I was learning, but in a bit of a disorganized way and I think that for white wine in particular, I was tasting wrongly. Then I started to taste intelligently, so to speak, because before that, I was tasting stupidly (laughs); I didn't have the right benchmarks. (Dany)

Of course, Dany, like everybody, knows how to rank and comment on qualities in greater or lesser degrees of detail. Yet he started to wonder about his ability to properly assess quality. He tried to be better at distinguishing good wines from bad ones, and their relevant appraisals. These doubts regarding their ability to assess wines opens a new realm of development in the amateur's activity.

\section{Learning to value}

Many wine guides, wine tasting courses and samplings support amateurs in learning how to assess the quality of wines by providing an 'expert' and competent judgment on the quality of wines. They all recommend first increasing the number of experiences with wine, to acquire 'experience', and insist on 'paying attention' to what one is drinking.

This notion of 'paying attention' is commonly interpreted as an intellectual technique used to sharpen perception by stimulating the brain's vigilance (Grasseni, 2004, Hennion and Teil, 2004, Köhler and Austin Adams, 1958, Hennion, 2007) or a socially-structured perceptual focus or 'gaze' (Crary, 1999, Lossau, 2005). Yet with amateurs, 'paying attention' is more likely to fit Teil (2019) alternative interpretation. By asking amateurs to pay attention, educationalists urge them not to take their perception for granted but instead to start questioning 
it: what does this wine 'really' taste of? Questioning alone does not provide answers; it only makes perception dubious, uncertain and ready for change.

Perception, for doubtful amateurs, has lost its usual character of unquestioned obviousness (Merleau-Ponty, 2012 [1945]). They are concerned by achieving 'good' perception and turn towards expert tasting tools and techniques, odour lexicons and blind test namely.

Language is decisive regarding olfactory proficiency. Many amateurs take interest in expert odour lexicons, some of them associating words with olfactory references in order to perfect sensory communication. Le Nez du Vin (Lenoir, 1981) is such a well-known collection of aromas. The boxed set contains 52 olfactory references: pineapple, hawthorn, blackberry, etc, but no 'sauvignon' or 'pinot noir' aromas. At the most, some aromas are said to be markers of certain wines, such as the peppery aroma of pinot d'Aunis. Those of the 'pineapple', 'hawthorn', or 'blackberry' vials are presented as wine aroma standards structuring the complexity of wine taste. Amateurs tend to first enthuse for all sorts of recognition games based on these sets of odours, but their use often develops beyond their standardization purpose. The odorous vials become 'examples' of wine smells thus supporting the amateurs' discovery of wines' taste variety. While repeatedly sniffing their wine glasses, they attempt first to unearth and smell the 'grapefruit' odour of chardonnay, followed by 'salty' or 'mineral' notes, or the complex 'smell of cabernet'. Furthermore, even though odour sets never contain any odour references for good and bad quality, their perception remains crucial. Amateurs want to know not only how to perceive wines flavours and to analyse their components, but also whether a wine is good or bad.

Wine amateurs are known for their blinded tastings, to which they subject themselves along with friends. These consist in trying to recognize the origin, grape variety, winemaking process, and so on of wines placed in a decanter.

Now and then I play the game [blinded tasting]. My wife puts the numbers on the decanters, and I participate on the same level as my guests. At the end of the day, you start off with the same level of chance, and even though I know my wine, sometimes I'm mistaken and am not necessarily successful in recognizing them, and that lets you continue your initiation in taste, colour, flavour, behaviourii. (Lou)

For those who 'play the game', blind tasting has the fundamental virtue of freeing perception of the 'influences', mostly what they call 'social influences', that bias it. This is why Ilian got 
rid of all his tasting notes: "I think that I was tasting incorrectly, with the bottle, knowing what it was". Within the corpus of studies of wine amateurs, very few authors have devoted attention to this technique and amateurs' concern for social aspects. Why are they so concerned with social influence?

Blind tasting supports a requirement for wine amateurs: being able to taste wines oneself, in order to assess them. Amateurs are inclined to denounce 'label-drinkers', those individuals who let themselves be 'influenced' by hearsay or reputation: they do not actually taste the wine, but simply repeat what others think about the wine. Amateurs who participate in blind tastings force themselves not to take into account tasting experiences other than their own present experience. Demossier (2005) is right: "the core of wine drinking culture as a cultural, symbolic and material object has come under attack"; yet this attack is fuelled by the amateurs themselves, because they require perception to be performed by the amateur him/herself.

Blind tasting is not only seen as freeing amateurs' perception from undesired influence; these tests "question your value as a taster" (Ilian). Increasing success in blind tests is interpreted as the result of increasing ability to accurately discriminate between wine qualities, which contributes to establishing the trustworthiness of a person's tasting comments. Unsurprisingly, they often result in frictions. Collective blind tests may therefore be considered as unnecessarily unpleasant games. Still, the issue is not blind tasting, but rather its use as a collective test of proficiency.

\section{The erosion of individual tastes and 'good quality'}

Amateurs' passion often starts when they embark on a dual quest: for good wines, and for true taste. Some of them acquire considerable knowledge, as well as tasting proficiency as per expert criteria. However, after a certain amount of time spent tasting limitlessly, testing their proficiency, and comparing wines, a shift may occur with respect to the taste and quality of wines, and gradually reinforce their quest.

Distastes are obstacles to discovery and must be tamed. For some wines considered 'difficult to like', amateurs submit themselves to all sorts of training to overcome disgust. The following amateur congratulated himself for finally managing to like vin jaune:

I didn't like vin jaune. He made me taste a vin jaune at the beginning of the year, and then made me taste one again three months later, and then again three 
months after that. The third or fourth time, I discovered that I liked vin jaune. (Sacha: 6)

This 'cultural goodwill' is not limited to distastes. Tastes are also an obstacle when they systematically orient choices; they too must be overcome.

I developed habits and inevitably reflexes [...]. Very quickly, when you're an expert, it's like with everything, when you get into your car, you drive without thinking. I'm not saying that I drink without thinking; not by any means. But I do have reflexes when it comes to my choices [...] I brought a couple of bottles of Saint-Joseph ${ }^{1}[\ldots]$ It was also to change our habits, to somewhat break away from the monotony of certain wines like the great classic Bordeaux. (Lou)

Sociologists interpret this individual injunction to like unpleasant things that other amateurs designate as highly valuable, as the sign for a social over-determination of taste and the transformation of an individual or collective enjoyment activity into a social process of hierarchization or a social competition for symbolic benefits (Bourdieu, 1979, Daenekindt and Roose, 2013, Lizé, 2016). This understanding focuses on a particular step in the amateurs' quest and sidelines the very aim of amateurs and what makes them different from other social actors: wine taste exploration.

The discovery of wines, driven by what amateurs call their 'natural curiosity' as well as by this voluntary undertaking of working on oneself and one's tastes, leads to what is commonly called the 'trajectories' of amateurs' taste:

I discovered wines, Burgundy. [...] That lasted for a long time. [...] I completely stopped tasting Bordeaux, completely rejected Bordeaux. I went to Burgundy. Now I've stopped tasting Burgundy in exchange for Languedoc and the Rhône. It's true that it happens in stages. (Ilian)

Step by step, amateurs discover and taste more and more wines. However, their growing experience does not make them increasingly familiar with the details of their tastes. On the contrary, by constantly revisiting them, re-questioning them, and moving beyond them, their tastes seem to crumble and then disappear: "I don't really have a preference, well, not anymore. I was for Côtes du Rhône because of my origins, but I stopped. There isn't... I like everything" (Sacha).

\footnotetext{
${ }^{1}$ Small Protected Denomination of Origin in the Southern Côtes du Rhône area
} 
The idea of good quality follows the same path.

Amateurs use blind tasting to protect their perception from external 'influences' and labels, which can cause people to mistake bad wines for excellent ones. Conversely, they can be used to reinforce the correct assessment of good wines, thus becoming resources to ensure that a wine will be judged for its 'true' value.

You know that when you come to my house, you'll find a wine of which very few bottles exist and which is the star of Languedoc, which is this or that... This is a part of the preparations... the psychological preparations, largely sympathetic magic, to consume that bottle, which I think it would be a shame to overlook, because according to me it's a great bottle. (Ilian)

Ilian is an all-out supporter of blind tasting to assess the 'true' quality of wines protected from 'sympathetic magic' exerted by names and fame. He is nonetheless arguing for the necessity to know the high quality of a wine beforehand, to be able to appreciate it for its true value. In one fell swoop, he swaps blind tasting and its virtues, for open tasting and the opposite virtues of the orientation of quality assessment. Tasting therefore shifts from a quality revelation activity to a production practice in which the quality of the wine is the result of a valuation process. Hugh Johnson, the author of several famous works on wine, wrote a pocket booklet, How to Enjoy Your Wine, in which he does not list great wines or famous wineries across the globe, but rather explains how to derive pleasure from wines regardless of what they are. Likewise, some amateurs state that there are no good or bad wines, not because they all have the same quality, but because there is always something interesting in a wine. One 'only' has to endeavour to emphasize its qualities via a personal undertaking or the use of the context, one's expectations, influences, and past experiences. They are filled with enthusiasm for those 'small, unpretentious wines' that are equally pleasant when properly presented, and are never short of new resources to this effect.

Tastes for good quality wines, along with taste proficiency, waver among these amateurs. One would imagine that they believe themselves to be sufficiently informed regarding assessment, or to have become experts when it comes to quality, and have nothing left to learn. Yet some of them are surprising, all the while arousing a degree of admiration. Despite their considerable experience in tasting wines, they refuse to allow themselves to 'know' that which is good and that which is not, and are therefore deemed to be particularly 'modest'. Yet their portrayal as 'modest' disregards the very sense of their interpretation of wine quality. They explain that 
everybody is capable of evaluating wine, and that it is not possible to say what constitutes a good wine: so many excellent wines have disappointed them and vice versa. The only way to know if a wine is good is by tasting it. However, one must always be cautious, as an assessment is always at risk of being revised shortly afterwards, by a new tasting. When such amateurs are also professionals, they may appear intriguingly 'schizophrenic'. During their professional activity, they assume that there is an objective quality and everyone should look and pay for it; yet the same evening, at dinner, the same person may start arguing that there is no such 'real' objective quality.

They see good quality as something to produce, a questioning with a result that is always uncertain, and that constantly needs be started afresh. Just as for tastes, the ideas of good wine quality per se wear out, as does tasting proficiency.

Differences in assessments do not fade. On the contrary, the individualization of tasting induced by blind tests fosters divergences in appreciation. Yet differences are trapped no longer in a gradient of trustworthiness but instead in a process of enrichment of the taste, which dissolves differences. One person smells pear and their neighbour, rhubarb. These amateurs make full use of others' experience to reveal olfactory facets that they failed to notice. They creep towards a non-normative conclusion on the diversity of perceptions - quite the opposite of aromas or wine recognition tests. During a tasting, a divergence in taste no longer signals a better appreciation of quality by a taster who is gaining more expertise, but rather, an opportunity to make the gustatory world richer and more complex.

The notions of taste, tasting proficiency, and good quality do not disappear; instead, they weaken as the determinants of that which a person likes, or descriptors of what wines are. They continue to play a decisive role in critical discussions between amateurs, like a point of articulation between the different products tasted and the different tasters. The assessment of wine quality is not devoid of criteria: the intensity or lightness, the finish, the freshness or the opulence, depending on the case, a floral or animal aroma. As for tastes, making good quality explicit supports its own challenge. It is not difficult to draw up technical specifications for good quality and to compose wines according to a set idea of quality. Producers have tried, and not without success. Yet they may have been stunned and angered at times by certain criticisms of their wines: a 'formulaic' quality, or 'manufactured', in other words, predictable.

These changes indicate a shift in amateurs' exploration: it is sustained no longer by the discovery of that which exists and more specifically good wines, but rather by the incessantly 
repeated fresh examination of wine awaiting unexpected manifestations, revelation, surprise. Like a novel re-read without tiring of it, a film you continue to discover even when you know it by heart, or a painting that changes every time that you look at it, these amateurs' great wines are those which renew upon each tasting. The world to discover is ever vaster: "you're never done with wine", says Chantal Lecouty (1987) in her guide, promising 'curious' amateurs a journey through an endless world to explore.

Just like learning about true quality, this incessantly repeated questioning of tastes is subject to the necessity of tasting. Learning puts emphasis on the taster: $\mathrm{s} / \mathrm{he}$ is the one performing the tasting, the results cannot be the simple repetition of others' opinions. Analogously, the questioning of tastes insists on anchoring the tasting in the wine. Tasting cannot consist in imagining, inventing, or dreaming of the world to produce. Taste must be a co-production of the taster and the wine.

This non-normative quest for tastes, which endows good quality and tasting proficiency with ephemerality, goes along with a change in amateur practices. The discovery of wines, tastes, and qualities turns to an exploration that is no longer sustained by the search for new wines or true quality and that suffices unto itself.

This departure from the objective normative framing of taste may take a variety of forms: a slow or sudden change or a dual regime within the exploratory activity. It is also used to revive or reorient the discovery of amateurs whose 'curiosity' appears to be waning. The wine tasting club host below, worried about the inhibition that blind tasting could provoke when seen as a test of skills explains how he 'removes the complex' of his students: if two people do not smell the same thing, it is not because one knows and the other does not, but rather because they do not have the same distribution of sensory receptors.

We aren't all the same. And the somewhat absurd side of people who make statements about wine... [I] bring the wine back to what it is, namely something quite simple, and later people get over their complex and afterwards we can talk about the taste of the wine and get them to say personal things about the wine. (Ilian)

Tastes shift and vary, and so much the better! Why try to change that? A few publications with evocative titles have made it their specialty to spur on these lukewarm amateurs, namely Wine for Dummies or Madame and the Wines. They recommend 'skipping' tasting ability acquisition and following your tastes while constantly seeking to broaden the range of what you like. 


\section{An exploration fuelled by alteration}

Whether wine, its tastes, and its qualities are to be discovered or known, for all amateurs they are objects of an exploration. The activity that generates passion for wine begets a world of wine that is constantly expanded, revisited, questioned, re-examined. All amateurs are always ready, corkscrew in pocket, to taste again and again wines that are highly renowned, expensive, rare, unknown, great deals; to test combinations of dishes and wines; to meet new tasters and amateurs; to visit collections. All of these trials are like 'little gems', to use the fine expression of the amateur below, which invite people to revive tasting.

Wine is first a culture, then there is an effect of collecting, of discovery, because you don't know what you're going to find inside the bottle [...] There's a whole set of little gems ${ }^{\mathrm{iii}}$ that become lodged in knowledge on wine, wines in general, and good wines of course. (Lou)

The world ceases to be 'what it is'. The continuous retesting of tastes in some way or another, the refusal to ever rely on previous knowledge, marks a change by these amateurs, which nothing excites more than challenging 'preconceived ideas':

25 years old! It was a Chablis grand cru Grenouille. It's great to taste things like that, because the idea had sunk into people's subconscious that for a great white wine to be able to age, it needs to be oaked. This is highly edifying and relativizes things enormously. (Dany)

The verb 'relativize' does a good job of highlighting the way the amateurs' quest undermines every previously learned, stabilized, certain or settled knowledge or practice. Tasting equipment, decanters, thermometers, rules of food and wine pairing, or the most reliable reputations, are the first victims, followed by guide scores or prices; the most expensive wines no longer fascinate them.

Wines that they had previously found to be charming all of a sudden can prove to be unpleasant; longstanding paragons of good wines progressively fade, while disregarded other ones turn out to be interesting. These amateurs never demand constancy with respect to taste; quite the contrary: good things have multiple 'facets', hidden virtues that are never discovered all at once, and as for tastes, they are 'dependent' on the wines, the occasion, or the company. A turn is occurring in their exploration. They take growing distance from the wine critics, whose selections and marks are seen less and less as worthy quality assessments. If amateurs continue to go to exhibitions or fairs, it is not to purchase the wine that they liked: "I go to the exhibition, 
but I go to meet people and discover or rediscover their wine" (Dany). These amateurs all eagerly await new impressions, sensations, tastes, and pleasures. The result, the quality and the tastes, are less important than the tasting itself. They fear neither displeasure nor distaste, but rather 'lassitude'. Tastings must be opportunities for new discoveries; but they no longer crucially depend on the product profusion of the wine market.

\section{Refreshing pleasure and experience}

Passion for wine is not an irrepressible chain of events leading to a limitless world; amateur practices also have their failures. Learning can, at times, lead to 'slumps' and shorter or longerlasting periods of concern related to unsatisfactory progress, as for Cande who saw no end to his learning:

And why do you like it, why do you ask yourself the reason for things, and wine is the answer to multiple things, like a movie that you watch at a certain age... if that happens you get different feelings depending on your age. A painting, wine: it's the same thing. You step into the world of wine and see that it's a tunnel with no end [...] The further I go into it, and this is not false modesty, the more I ask myself questions and the fewer answers there are. It's really complicated and it doesn't stop getting ever more complicated. You step in [...] to this labyrinth. At the entrance, you say that it's very easy and this or that wine there... But you have to be increasingly cautious the further you go in. [...] Observation [...] and sensation. And silence, like the Trappists. (Cande)

Or this other amateur, for whom learning and discovering tastes, which is so smooth and pleasant to others, feels very demanding:

When you have a palate used to tasting a certain type of wines... it's very difficult and requires an enormous amount of work on yourself to be able to learn to taste other wines, other appellations, other countries; it's very, very hard.

I think that... it requires an enormous personal effort. (Alex: 11)

Learning can be slow: perception does not improve, no particularly delicious world seems to appear; you make no progress, the world does not change; does the promised superior quality really exist? Some people put the blame on their physiological insensitivity, while others give up, disappointed by what they call a pointless 'social practice'. 
It is not only the beginnings that can be difficult; once started, passion does not maintain itself on its own. All amateurs may see it wane one day:

I'd like to return to something simpler; to make the difference between tasting and the act of drinking wine. I like to drink wine. I like the effect of the alcohol in the wine. I like to be able to talk a bit more, as I have trouble being social and wine really helps me to talk. I'd like to rediscover this aspect of pleasure and disassociate it from tasting. I think that constantly having an analyst's attitude isn't very practical. So, right now I'm effectively withdrawing from tasting as well as consumption. (Ilian)

Ilian is a passionate amateur who, during his Burgundy period, opened two to three bottles a day, hosted a wine tasting club, became a sensory analysis researcher, and then bought vines. By the time of this interview, he had a problem with wine: the "little gems" no longer tantalized him; his pleasure was dying out. He was growing weary. Tasting had become an excessively regulated analytical exercise and he felt his pleasure of drinking wine was becoming a pleasure of becoming intoxicated. He was trying to put this aside, seeking to renew his pleasure, to refresh his relationship with wine, to find greater simplicity, or as others say, to 'revirginize' his relationship with wine.

Amateurs are not bereft of resources when faced with waning pleasure, tastings that become repetitive, enthusiasm that is burning out. To maintain or regain the 'virginity' or 'freshness' of their perception, the ability to be surprised, to circumvent stifling expectations, some of them cease to drink certain specific wines and switch to something else, generating these taste 'phases'. Others, more drastically, practice abstinence: for a varying period of time, they may decide to suspend their consumption, hoping to rediscover an appetite, a curiosity, a new palate. But the most common technique of 'revirginizing' taste is, most certainly, blind tasting.

Blind tasting is an essential tool for amateurs, and one with multiple uses. It allows one to better perceive 'true' quality, to assess tasting 'proficiency', and to ensure the taster that it is in fact he or she who is tasting and analysing his or her experience anchored to wine. It is once again used to refresh tasting. Like a music lover who tunes in to a radio station to listen to the music playing, without having chosen it, or a person who randomly picks a wine or a CD from the shelf, wine amateurs use blind tasting to overcome their own 'reflexes', to taste without knowing, as if it were the first time. In their hands, it becomes an instrument to maintain their 
experience unstable ${ }^{\text {iv }}$. This usage deeply contrasts with that of sensory analysis, on which amateurs' learning is grounded.

\section{Conclusion}

To be an amateur is a performance, one that keeps exploration alive. Exploration veers away from the discovery that ends once the lost city is discovered. It feeds on the uncertainties it generates; the 'pleasure' of surprise fuels the 'excitement' of exploring a wine that remains unknown. Yet pleasure and excitement, like curiosity, are neither explanations nor requirements, but only psychological interpretations acknowledging the vitality of amateurs' exploration.

Amateurs' exploration is not just an activity akin to a play or a game, that is, a set of practices, people, rules and objects. The beings it involves transform with its unfolding, showing more or less differentiated stages or interfering regimes with their own wines and tasting theories, uncertainties, practices and equipment. Studies on amateurs have focused on the normative moment of the often-initial discovery phase. This particular moment is fostered by the amateurs' distrust of their own ability to taste the wines properly, which causes them to seek help from other norm-producing collectives: sensory sciences, sommeliers, wine-critics, and other wine professionals such as retailers or wine-growers. Though it draws attention - for better or for worse -, it is just one stage of the exploration, albeit a flourishing stage in the case of wine exploration. Still, like the tree, it should not conceal the wood and the transformations fostered by exploration.

Unpredictability is at the core of amateurs' exploration, which fosters the instability of tastes and qualities through continuous wine discoveries, and then repeated tastings. It may be tempting to oppose these two stages of exploration: a quest for what exists, and what will happen; in other words, a positivistic framing of experience and a more pragmatic one. Yet whatever the framing, taste discovery or performance, experience is always renewed: a distinctive mark of these amateurs. Consequently, tastes, as well as 'good' quality, understood as markers of the taster and of the wines, dissolve. In contrast with the 'closure' resulting from routinization and habituation, amateurs' exploration fosters the emergence of a ceaselessly changing world and a concomitant evanescence of tastes and qualities. This erosion of the idea of wine quality could be worth comparing with the reflexive deconstruction of art's worth, in pictorial art namely. Still, the qualities and tastes of wines do not disappear; they are the 
distributed yet always temporary result of the continuous testing of the wine by the tasters, from one new tasting to the next. In the course of exploration, tools required for 'true' perception can turn to resources enriching the equipment for the production of 'good' taste. From this point of view, the facilitator Ilian is particularly interesting: while pursuing a quest for 'true' perception devoid of influences and teaching tasting classes, he emphasizes the idiosyncrasy and incommunicability of tastes due to the diversity of individual sensory physiologies, describes himself as not having tastes, and readily uses influences to ensure that his guests do not miss a good wine. This is not incoherence but tasting virtuosity.

Finally, the pragmatic entry into the amateurs' taste topic enables beings remote from the usual objects and subjects of consumption to emerge.

Wine's attractivity changes significantly; its 'prestige' may open a door to exploration, but then wane. "Wine is something quite simple", said Ilian during his wine classes. Wine diversity, however, is a major driver of discovery, as in the case of paintings. When wine turns to a sort of living art where each new tasting feeds exploration, this diversity takes on a whole new dimension. The resulting endless renewal of wine is widely acknowledged as that of the original or long-lasting masterpiece, tirelessly contemplated and able to renew itself and adapt to changing publics. The comparison of wine amateurs with other amateurs (Hennion and Teil, 2003) suggests that the taste transformation attached to exploration extends to other passions, though with peculiarities. Hierarchical quality evaluations do not permeate all domains as much as they do wine, music, or sports. Collectors of non-marketed goods, for instance, may therefore experience less differentiated phases during their quest.

Amateurs' developing tasting experience could still make them appear as 'knowledgeable' wine-drinkers, owing to both their extended repertoire of wines and their ability to assess wines. But this experience does not translate into any positive knowledge nor support any knowledge hierarchization or normalization. As their exploration unfolds, their tastes, understood as determining or structuring action and consumption, erode. They leave the floor to series of provisional and ever incomplete valuations. This taste transformation contributes to deeply blurring the significance of taste indicators like repertoire, likes, or techniques, and their ability to support a lasting social stratification of taste. Tastes resulting from exploration are fundamentally unstable, and thus hardly fit the picture of the taste-prescribing intermediary.

Lastly, the amateurs of this study have engaged in a sustained and exclusive exploration that induces a certain evanescence of tastes and qualities. Less invasive exploration may infiltrate 
other regimes of activity which are framed more strategically or 'familiarly' (Thévenot, 2006), and possibly contribute to the omnivorous relaxation of class distinction (Peterson and Kern, 1996, Holt, 1997, Hazır and Warde, 2015, Yalvaç and Karademir Hazır, 2020). Moreover, drinkers who do not question the obviousness of experience and who let it be carried along by the flow of habit, for instance, would surely participate in the emergence of more structuring tastes. Yet the resulting realities emerging from such other regimes of activity are yet to be systematically accounted for.

\section{References}

Abbots, Emma-Jayne 2018 Corporeal Crafting: Tastes, Knowledges and Quality Protocols in British Cider-Making. In: Pavoni, Andrea, Mandic, Danilo, Nirta, Caterina, et al. (eds.) Taste. University of Westminster Press.

Becker, Howard 1963. Outsiders, New york, Free Press.

Beckert, Jens, Rössel, Jörg and Schenk, Patrick 2017. Wine as a Cultural Product:Symbolic Capital and Price Formation in the Wine Field. Sociological Perspectives, 60, 206-222.

Benzecry, Claudio E. 2012. Opera Thugs and Passionate Fandom. Contexts, 11, 39-45.

Bourdieu, Pierre 1979. La distinction - Critique sociale du jugement, Paris, Editions de Minuit.

Bourdieu, Pierre 1992. Les règles de l'art. Genèse et structure du champ littéraire, Paris, Seuil Points Essais.

Cowen, Tyler 1989. Are all tastes constant and identical?: A critique of Stigler and Becker. Journal of Economic Behavior \&amp; Organization, 11, 127-135.

Crary, Jonathan 1999. Suspensions of Perception: Attention, Spectacle, and Modern Culture, Cambridge, MA, The MIT Press.

Daenekindt, Stijn and Roose, Henk 2013. Cultural chameleons:Social mobility and cultural practices in the private and the public sphere. Acta Sociologica, 56, 309-324.

Dannefer, Dale 1981. Neither Socialization Nor Recruitment: The Avocational Careers of OldCar Enthusiasts. Social Forces, 60, 395-413.

De Benedittis, Mario 2019. Expert Wine Tasting as a Social Practice: An Enactive Ethnography. Sociologica, 13, 135-147.

Demossier, Marion 2005 Consuming Wine in France: The "Wandering" Drinker and the Vinanomie. In: T., Wilson (ed.) Drinking Cultures. Oxford: Berg.

Demossier, Marion 2010. Wine Drinking Culture in France: A National Myth or a Modern Passion?, UK, University of Wales Press.

Denora, Tia 1995. The Musical Composition of Social Reality? Music, Action and Reflexivity. The Sociological Review, 43, 295-315.

Dubois, Vincent, Meon, Jean-Matthieu and Pierru, Emmanuel 2013. The Sociology of Wind Bands Amateur Music Between Cultural Domination and Autonomy, Routledge. 
Entwistle, Joanne 2006. The Cultural Economy of Fashion Buying. Current Sociology, 54, 704724.

Flichy, Patrice 2012. Le sacre de l'amateur : sociologie des passions ordinaires à l'ère numérique, Paris, Seuil.

Grasseni, Cristina 2004. Skilled vision. An apprenticeship in breeding aesthetics. Social Anthropology, 12, 41-55.

Gravina, Giampaolo 2012. A Matter of Taste. The semi-serious musings of a wine taster on the contentious prospects of professional tasting. rivista di estetica, 51, 149-154.

Groves, Ronald, Charters, Steves and Reynolds, C. 2000. Imbibing, Inscribing, Integrating and Imparting: A Taxonomy of Wine Consumption Practices. Journal of Wine Research, 11, 209222.

Hazır, Irmak Karademir and Warde, Alan 2015 The cultural omnivore thesis. In: Hanquinet, L. and Savage, M. (eds.) Routledge International Handbook of the Sociology of Art and Culture. Taylor \& Francis.

Hennion, Antoine 2001. Music Lovers:Taste as Performance. Theory, Culture \& Society, 18, $1-22$.

Hennion, Antoine 2007. Those Things that Hold us Together. Taste and Sociology. Cultural Sociology, 1, 97-114.

Hennion, Antoine and Teil, Geneviève 2003 Les protocoles du goût, une sociologie positive des grands amateurs de musique. In: Donnat, O. (ed.) Regards croisés sur les pratiques culturelles. Paris: La documentation Française.

Hennion, Antoine and Teil, Geneviève 2004 Le goût du vin. Pour une sociologie de l'attention. In: Nahoum, Véronique and Vincent, Odile (eds.) Esthétiques du quotidien. Paris: Editions de la MSH.

Holt, Douglas B. 1995. How Consumers Consume: A Typology of Consumption Practices. Journal of Consumer Research, 22, 1-16.

Holt, Douglas B. 1997. Distinction in America? Recovering Bourdieu's theory of tastes from its critics. Poetics, 25, 93-120.

Howland, Peter J. 2013. Distinction by proxy: The democratization of fine wine. Journal of Sociology, 49, 325-340.

Jamerson, Heather 2009. Intoxicators, educators, and gatekeepers: The enactment of symbolic boundaries in Napa Valley wineries. Poetics, 37, 383-398.

Köhler, Wolfgang and Austin Adams, Pauline 1958. Perception and attention. The American Journal of Psychology, 71, 489-503.

Lecouty, Chantal 1987. Madame et les vins, Paris, MA Editions.

Lenoir, Jean 1981. Le nez du vin, Editions jean Lenoir.

Lizé, Wenceslas 2012 Trajectoires biographiques et itinéraires d'amateurs. Une enquête sur le goût musical. In: Chantegros, S. , Orange, S., Pégourdie, A., et al. (eds.) La fabrique biographique. Limoges: PULIM.

Lizé, Wenceslas 2016. Une micro-économie des biens symboliques. Hiérarchisation des valeurs musicales et construction du goût au sein d'un cercle de jazzophiles. Regards sociologiques, $49,85-102$. 
Lossau, Julia 2005. The body, the gaze and the theorist: remarks on a strategic distinction. Cultural Geographies, 12, 59-76.

Maisonneuve, Sophie, Teil, Geneviève and Hennion, Antoine 2002. Le goût comme un « faire ensemble ». Une comparaison entre le goût alimentaire et le goût musical. Paris: Rapport pour la Mission du patrimoine.

Majumdar, Saikat 2017. The Critic as Amateur. New Literary History, 48, 1-25.

Merleau-Ponty, Maurice 2012 [1945]. Phenomenology of Perception, London, New York, Routledge.

Mount, Harry 2006. The monkey with the magnifying glass: Constructions of the connoisseur in eighteenth-century Britain. Oxford Art Journal, 29, 167-+.

Negus, Keith 2002. The work of cultural intermediaries and the enduring distance between production and consumption. Cultural Studies, 16, 501-515.

Overton, John and Murray, Warwick E. 2013. Class in a Glass: Capital, Neoliberalism and Social Space in the Global Wine Industry. Antipode, 45, 702-718.

Perullo, Nicola 2012. Wineworld: Tasting, Making, Drinking, Being. Rivista di Estetica, 51, 348.

Peterson, Richard A. and Kern, Roger M. 1996. Changing Highbrow Taste: From Snob to Omnivore. American Sociological Review, 61, 900-907.

Platt, Richard 2000. New light on Richard Mudge, 1718-63 - Some aspects of social status and amateur music-making. Early Music, 28, 531-545.

Rössel, Jörg, Schenk, Patrick and Eppler, Dorothea 2018. The emergence of authentic products: The transformation of wine journalism in Germany, 1947-2008. Journal of Consumer Culture, $18,453-473$.

Schwarz, Ori 2013. Bending Forward, One Step Backward: On the Sociology of Tasting Techniques. Cultural Sociology, 7, 415-430.

Sherman, Rachel 2011. The Production of Distinctions: Class, Gender, and Taste Work in the Lifestyle Management Industry. Qualitative Sociology, 34, 201-219.

Silverstein, Michael 2006. Old Wine, New Ethnographic Lexicography. Annual Review of Anthropology, 35, 481-496.

Silverstein, Michael 2016 Semiotic Vinification and the Scaling of Taste. In: Summerson Carr, E. and Lempert, Michael (eds.) Scale - Discourse and Dimensions of Social Life. California: University of California Press.

Smith Maguire, Jennifer 2010. Provenance and the liminality of production and consumption: The case of wine promoters. Marketing Theory, 10, 269-282.

Smith Maguire, Jennifer 2018. The taste for the particular: A logic of discernment in an age of omnivorousness. Journal of Consumer Culture, 18, 3-20.

Smith Maguire, Jennifer and Matthews, Julian (eds.) 2014. The Cultural Intermediaries Reader: SAGE Publications.

Sneijder, Petra and Te Molder, Hedwig F. M. 2005. Disputing taste: Foods pleasure as an achievement in interaction. Appetite, 45, 51-61.

Stebbins, Robert A. 1977. The amateur - Two sociological definitions. Pacific Sociological Review, 20, 582-606. 
Stebbins, Robert A. 1979. Amateurs : On the Margin Between Work and Leisure, Beverly Hills, Sage.

Sternsdorff Cisterna, Nicolas 2014. Unexpected Moments and the Wine Experience. Food and Foodways, 22, 90-111.

Stiegler, Bernard 2011. Le temps de l'amatorat. Alliage [Online], 69. http://revel.unice.fr/alliage/index.html?id=3272.

Teil, Geneviève 2009. A la recherche du plaisir. Une analyse pragmatique de la perception. In: Berthon, Salomé, Chatelain, Sabine, Ottavi, Marie-Noëlle, et al. (eds.) Ethnologie des gens heureux. Paris: Editions de la MSH - Coll. Cahiers d'ethnologie de la France.

Teil, Geneviève 2019. Learning to smell: on the shifting modalities of experience. The Senses and Society, 14, 330-345.

Teil, Geneviève and Hennion, Antoine 2004 Discovering Quality or Performing Taste? A Sociology of the Amateur. In: Harvey, Mark, Mcmeekin, Andrew and Warde, Alan (eds.) Qualities of Food: Alternative Theoretical and Empirical Approaches. Manchester: Manchester University Press.

Terrio, Susan J. 2000. Crafting the Culture and History of French Chocolate, Berkeley and Los Angeles, University of California Press.

Thévenot, Laurent 2006. L'action au pluriel. Sociologie des régimes d'engagement, paris, La Découverte.

Toffler, Alvin 1980. The third wave, New York, NY, William Morrow.

Tomasi, Gabriele 2012. On Wines as Works of Art. Rivista di Estetica, 51, 155-174.

Van Den Haak, Marcel and Wilterdink, Nico 2019. Struggling with distinction: How and why people switch between cultural hierarchy and equality. European Journal of Cultural Studies, $22,416-432$.

Vannini, Phillip, Ahluwalia-Lopez, Guppy, Waskul, Dennis, et al. 2010. Performing Taste at Wine Festivals: A Somatic Layered Account of Material Culture. Qualitative Inquiry, 16, 378396.

Whittenburg Ozment, Elizabeth 2015. The sociology of musical networks. International Sociology, 30, 448-456.

Wright, David 2005. Mediating production and consumption: cultural capital and 'cultural workers'. The British Journal of Sociology, 56, 105-121.

Yalvaç, N Simay and Karademir Hazır, Irmak 2020. Do Omnivores Perform Class Distinction? A Qualitative Inspection of Culinary Tastes, Boundaries and Cultural Tolerance. Sociology, 0, 0038038520967257.

Zhang, Jinghong 2018. Rituals, discourses, and realities: Serious wine and tea tasting in contemporary China. Journal of Consumer Culture, 0, 1-19.

\footnotetext{
${ }^{\text {i }}$ If asked, which was not always the case, I answered that I worked on taste and quality on the wine market.

${ }^{\text {ii }} \mathrm{He}$ is speaking of how wine behaves, depending on its ageing or the tasting circumstances.
} 
iii "Gems" tries to render the French "piment" conveying the idea of something that enlivens or intensifies.

iv This ability at renewing experience echoes and even sheds some light on some slightly enigmatic authors' claims on artworks, which are: "intrinsically unfinished, infinite and revived with each new experience of the gaze falling on it." Stiegler, Bernard 2011. Le temps de l'amatorat. Alliage [Online], 69. Available: http://revel.unice.fr/alliage/index.html?id=3272.: 161. 